\title{
Growth Hormone and Insulin-Like Growth Factor-I in Alzheimer's Disease
}

\author{
José Manuel Gómez Sáez ${ }^{*}$
}

\author{
Servicio de Endocrinología y Nutrición, Hospital Universitario de Bellvitge, Facultad de Medicina, Universidad de \\ Barcelona, CIBERDEM, L'Hospitalet de Llobregat, Barcelona, Spain
}

\begin{abstract}
Alzheimer's disease (AD) is a major public health issue in the ageing population. For decades, research focused on studies using neurochemistry and biochemistry to understand the mechanisms underlying this disease. Recently, emerging evidence supports the concept that $\mathrm{AD}$ is also a disorder of metabolic degeneration. Amyloid beta-peptide is central to the pathogenesis of $\mathrm{AD}$, and the $\mathrm{AD}$ brain is under intense oxidative stress, including membrane lipid peroxidation. Amyloid beta-peptide causes oxidative stress and neurotoxicity to neurons. Neurochemical changes in the brain from patients with $\mathrm{AD}$ indicate multiple disturbances and it seems likely that the changes are secondary to more fundamental changes into the brain. Based on decreased IGF-I concentrations in AD, some authors have suggested that disrupted IGF-I input to the brain may be involved in the pathogenesis of amyloidosis and changed IGF-I signalling may potentially lead to amyloidosis. Disrupting IGF-I signalling in the coroid plexus is sufficient to trigger pathological changes as those observed in $\mathrm{AD}$ and brain $\beta$-amyloid increases as consequence of its lower clearance. The IGF-I is a potent neurotrophic as well neuroprotective factor found in the brain with a wide range of actions in both central and peripheral nervous system. IGF-I is a critical promoter of brain development and neuronal survival and plays a role in neuronal rescue during degenerative diseases. So, an emerging clinical targets for improving the quality of life with ageing or for improving clinical manifestations of AD may be activation of GH/IGF-I that rejuvenate the axis to result in overall physiological benefit, with a potential of prevent or reverse detrimental age-related or AD changes in the brain.
\end{abstract}

Keywords: Alzheimer's disease, $\beta$-amyloid, growth hormone, growth hormone releasing hormone, insulin-like growth factor-I.

\section{INTRODUCTION}

Dementia disorders are syndromes in which there is evidence of decline in memory and thinking, deterioration of emotional functions and impairment of motor performance sufficient to impair functioning in daily live. The classification of dementias must be made on different levels, and usually they are subgrouped as primary degenerative dementias, vascular dementias and secondary dementias. Alzheimer's disease (AD) is the most common dementing illness in the elderly ( $54 \%$ of all cases of dementia), and is a progressive neurodegenerative disorder characterized by insidious onset with cognitive impairment and affecting mental function, amnesic type of memory impairment, visuospatial deficits, deterioration of language and selfsufficiency and inexorable progression; is a leading cause of morbidity and mortality in geriatric population [1]. Clinical criteria for the diagnosis of AD include insidious onset and progressive impairment of memory and other cognitive functions. There are no motor, sensory, or coordination deficits early in the disease. The diagnosis cannot be determined by laboratory tests. These tests are important primarily in identifying other possible causes of dementia

*Address correspondence to this author at the c/ Sabino De Arana 40, $3^{\circ}, 2^{\mathrm{a}}$ 08028, Barcelona, Spain; Tel: 34-93-3306522, 34-686480075; Fax: 34-932607846; E-mail:jmgs@bellvitgehospital.cat that must be excluded before the diagnosis of AD may be made with confidence. Neuropsychological tests provide confirmatory evidence of the diagnosis of dementia and help to assess the course and response to therapy. The criteria proposed are intended to serve as a guide for the diagnosis of probable, possible, and definite $\mathrm{AD}$; these criteria will be revised as more definitive information become available.

$\mathrm{AD}$ is a major public health issue in the ageing population. For decades, research focused on studies using neurochemistry and biochemistry to understand the mechanisms underlying this disease. Recently, emerging evidence supports the concept that $\mathrm{AD}$ is also a disorder of metabolic degeneration. Studying the roles of insulin, growth hormone (GH), insulin growth factor-I (IGF-I), cholesterol and adipokines in the pathogenesis of $\mathrm{AD}$ opens new doors to understanding the cause and dysfunction with Amyloid beta-peptide [Abeta(1-42)] is central to the pathogenesis of $\mathrm{AD}$, and the $\mathrm{AD}$ brain is under intense oxidative stress, including membrane lipid peroxidation. Abeta(1-42) causes oxidative stress and neurotoxicity to neurons in mechanisms that are inhibited by vitamin $\mathrm{E}$ and involve the single methionine residue of this peptide. In particular, Abeta induces lipid peroxidation in ways that are inhibited by free radical antioxidants. Abeta(1-42) addition to synaptosomes, thereby coupling increased Abeta(1-42) in AD brain and increased lipid peroxidation and its sequelae and possibly explaining the mechanism of glutamate transport inhibition 
known in AD brain. Implications of these findings relate to decreased energy utilization, altered assembly of cytoskeletal proteins, and increased excitotoxicity to neurons by glutamate, all reported for $\mathrm{AD}$. The lipid carrier protein apolipoprotein $\mathrm{E}$ allele is a risk factor for AD. These results are consistent with the notion of a coupling of the oxidative environment in $\mathrm{AD}$ brain and increased risk of developing this disorder. Taken together, the findings from in-vitro studies of lipid peroxidation induced by Abeta(1-42) and postmortem studies of lipid peroxidation (and its sequelae) in AD brain may help explain the apolipoprotein E allelerelated risk for $\mathrm{AD}$, some of the functional and structural alterations in $\mathrm{AD}$ brain, and strongly support a causative role of Abeta(1-42)-induced oxidative stress in $\mathrm{AD}$ neurodegeneration $[2,3]$..

Such effects are mediated by inflammatory cytokines released following microgliosis by $\beta$-amyloid, resulting in learning and memory deficits [4].

A somatostatin deficit occurs in the cerebral cortex of AD patients without a major loss in somatostatin-containing neurons. This deficit could be related to a reduction in the rate of proteolytic processing of peptide precursors. Since the two proprotein convertases (PC) 1 and $\mathrm{PC} 2$ are responsible for the processing of neuropeptide precursors directed to the regulated secretory pathway. Cortical somatostatin concentrations have also been reported to be reduced to varying degrees in $\mathrm{AD}$ patients, with a loss of cortical somatostatin receptors and reduced cerebrospinal somatostatin concentrations. The cortical somatostatin defect is not due to convertase alteration occuring during $\mathrm{AD}$. Further studies will be needed to assess the mechanisms involved in somatostatin deficiency in AD. Deficits in somatostatin and corticotropin-releasing factor are well recognized as prominent neurochemical deficits in $\mathrm{AD}$. The question of whether these profound neuropeptidergic deficits found in patients with end-stage disease extend into those with much earlier disease is relatively unanswered.

Within this context, reducing $\mathrm{AD}$ amyloidosis represents one of the main therapeutic strategies for $\mathrm{AD}$. On the other hand, $A D$ is associated with significant structural and functional changes in many peptide in the brain and it is well known that these peptides are important for communication. Some peptides function as neurotransmitters or neuromoduladors. The most consistent change within the brain is degeneration of cholinergic projections from the basal forebrain to the hippocampus and neocortex [5-7]. The infracortical white matter of the adult human cerebral cortex, interstitial cells, showing somatostatin expression is susceptible to developing the AD- related cytoskeletal changes; the progression in cytoskeleton changes is accompanied by loss of somatostatin [8,9]. $\mathrm{AD}$ is also associated with significant structural and functional changes in the noradrenergic system [10], corticotropin -releasing factor immunoreactivity and opioid peptides [11-13].

Taken together, the neurochemical changes reported in the brain from patients with $\mathrm{AD}$ indicate multiple disturbances and at the present level of knowledge, it is not possible to single out any of these changes as bring of special significance for de disease and it seems likely that the changes are secondary to more fundamental alterations in the brain.

\section{GROWTH HORMONE AND INSULIN-LIKE GROWTH FACTOR-I AND COGNITIVE DECLINE IN THE ELDERLY}

Physiological decline of GH and insulin-like IGF-I with ageingIGF-I axis with ageing [14-16] and the possibility that the GH/IGF-I axis is involved in cognitive deficits has been recognized for several years. Much new knowledge has been gained in the previous decades concerning the function of the IGF-I system. It is an exceedingly complex system, in large part due to the essentially ubiquitous role played in controlling growth processes at the cellular level. The regulation of the IGF-I system is not limited to systemic GH. Furthermore, a report has also shown that targeted deletion of the ALS gene, which also results in a large $(60 \%)$ reduction in circulating IGF-I levels, is associated with only minor effects on growth rate and no discernable effects on glucose metabolism. It has been suggested that a possible reason for maintaining such high levels of circulating IGF-I is to keep GH secretion in check. It remains uncertain whether plasma IGF binding proteins, especially IGFBP3 concentrations are directly stimulated by GH, alone, by IGFI alone, or both GH and IGF-I, but the reported decrease in IGFBP3 is probably a consequence of a decrease in the secretion of GH and IGF-I [14,17]. The concept that GH and IGF-I are required for normal development of the mammalian body and, more recently the brain, is supported by a vast experimental literature. IGF-I crosses the bloodbrain barrier and in recent years, much attention has focused on age-related decreases in serum GH and IGF-I as potential mechanisms that may influence cognitive function in the elderly. However, interventional studies are needed to establish a definite link between these hormones and function of the aging brain. In some studies, serum total IGFI and the total IGF-I to IGFBP3 ratio were inversely related to cognitive decline in the next two years of follow-up [1822].

As GH secretion is one of the main regulators of circulating IGF-I and IGFBP3, this finding suggest that GH secretion plays a important role in age-related cognitive decline. However free IGF-I concentrations are not associated with cognitive decline [23] and free IGF-I concentrations are probably a better indicator of $\mathrm{GH}$ secretion than total IGF-I and free IGF-I is the major IGF-I component responsible of the GH suppression [24]. In addition, some authors, observed that the Mini-Mental State Examination scores in elderly subjects, were not related to basal GH or GH response after GHRH stimulation, whereas they were positively related with IGF-I concentrations. GH secretion areas after GHRH were inversely correlated with body mass index, but no further correlations between $\mathrm{GH}$ data and clinical or nutritional parameters were found in a a study [25]. IGF-I concentrations were directly correlated with Mini Mental State Examination scores, being lowered in patients with more advanced cognitive deterioration, and with mid-arm circumference values, the decrease of which is 
thought to reflect protein caloric malnutrition, but not with body weight, BMI and decreased physical activity possibly take part in affecting IGF- I function in subjects with mild cognitive impairment and, reciprocally, IGF-I decrement might affect neuronal function [25].

In GH deficiency in adults a state where the psychosocial functioning and the worse quality of life in patients with pituitary insufficiency than in controls; those who are receiving conventional GH replacement therapy improve the quality of life. The possible negative effects of pituitary surgery, treatment with irradiation, and suboptimal replacement regimens with hormones other than GH on mood, behaviour and cognitive functioning are also present. The influence of GH deficiency per se, and the outcome of $\mathrm{GH}$ in adult patients are addressed in these cases with a possible mechanism for a direct effect of $\mathrm{GH}$ on the brain $[26,27]$.

\section{INSULIN-LIKE GROWTH FACTOR-I AXIS IN ALZHEIMER'S DISEASE}

Specific mutations in Abeta PP have been found in patients inheriting familial AD. These mutant Abeta PP proteins cause cell death in neuronal cell lines in vitro, but the molecular mechanism of cytotoxicity has not yet been clarified completely. A study demonstrated that the signaling pathway activated by mutated Abeta PP in the primary neurons is the same as that by the other artificial insults such as antibody binding to Abeta PP and the artificial dimerization of cytoplasmic domain of Abeta PP. The potential of neurotrophic factors and cytokines in $\mathrm{AD}$ therapy is also indicated. Studying cytotoxic mechanism of the London-type 2, IGF-I and humanin, preserve the neurons of the amyloid precursor protein toxicity as neuroprotective factors [28].

The plasma IGF-I concentrations were determined in family members carrying the Swedish amyloid precursor protein (APP) 670/671 mutation with or without AD and in age-matched controls from the same family. Plasma GH and prolactin concentrations were also determined. Measurement of the plasma IGF-I concentrations revealed a significant reduction only in the family members with $\mathrm{AD}$ compared to age-matched controls. However, there was no significant difference in the levels of $\mathrm{GH}$ and prolactin between the mutation carriers with or without $\mathrm{AD}$ and their respective age-matched controls. These findings indicate that the mechanisms regulating $\mathrm{GH}$ and prolactin were preserved and those regulating IGF-I concentrations might be affected in AD patients with the Swedish APP 670/671 mutation. [29]; also insulin as IGF-I concentrations are altered in many other types of human degenerative diseases [30]. On the other hand, the ability of IGF-I to cross the blood-brain barrier, strongly suggest that IGF-I interacts directly with the brain [31].

Changes in the hypothalamus-pituitary-adrenal axis function, entailing elevated cortisol circulating titres, occur in ageing and in some neurological conditions, such as AD and excess cortisol has neurotoxic effects which affect hippocampal neurones. Dehydroepiandrosterone sulphate has an antiglucocorticoid activity and neuroprotective effects. Cortisol was directly, and IGF-I inversely correlated with cognitive impairment. In AD patients alterations in hypothalamus-pituitary-adrenal axis function and elevated cortisol/ dehydroepiandrosterone sulphate ratio are related to lowered total and free IGF-I levels. These findings and their relationship to cognitive impairment suggest that changes in hormonal set-up might influence the clinical presentation of the disease [32]. Postmortem investigations revealed decreased expression of cerebral IGF-I receptor and insulin receptor substrate proteins in patients with $\mathrm{AD}$. Thus, impaired IGF-I/ insulin receptor substrate-2 signaling prevents premature death and delays amyloid accumulation in a model of $\mathrm{AD}[22]$.

\section{INTERACTIONS BETWEEN INSULIN-LIKE GROWTH FACTOR-I SYSTEM, INSULIN AND ALZHEIMER'S DISEASE}

In $\mathrm{AD}$, postmortem investigations revealed decreased expression of IGF-I receptor and insulin receptor substrate proteins. IGF- I is a potent neurotrophic as well as neuroprotective factor found in the brain: virtually all brain regions possess IGF-I binding sites, and IGF-I receptors are ubiquitously expressed. The mechanisms of Abeta toxicity are not clear but likely involve free radicals and apoptosis. Much interest is currently aiming at developing effective approaches to block Abeta toxicity in order to slow down disease progression. In that context, is interesting studying the role of IGF-I and purported free radical scavengers as blockers of Abeta toxicity in a simple in vitro model of hippocampal primary cultures. It has been observed that both IGF-I and some free radical scavengers are unique in that they are able not only to protect but even to rescue neurons against Abeta toxicity. These results are possible mechanisms of action to explain the protective properties of these two classes of agents [32,33]. IGF-I that is actively transported through the blood-brain barrier, but the specific mechanism for this process of transport is poorly understood; since IGF-I is also produced in endothelial and smooth muscle cells, the possibility exists that both plasma IGF-I and vascular-derived IGF-I are the primary sources of IGF-I for the brain. The stimulation of IGF-I receptors can activate intracellular pathways implicating a PI3/Akt kinase and CREB phosphorylation or modulate the production of free radicals. The effects, particularly those of IGF-I on key markers of the $\mathrm{AD}$ brains namely cholinergic dysfunction, neuronal amyloid toxicity, tau phosphorylation and glucose metabolism suggest the potential usefulness of this growth factor in the treatment of neurodegenerative diseases. However, the poor bioavailability, enzymatic stability and brain penetration of IGF-I hamper progress in this regard. The recent development of a small, non-peptidyl mimetic of insulin able to directly activate the insulin receptor suggests that a similar strategy could be used for IGF-I and the IGF-I receptor leading to the characterization of IGF-I mimics of potential clinical usefulness. [20,33-36].

There was a trend towards a reduction in neuronal loss after IGF-I administration. IGF-2 alone increased neuronal loss in the hippocampus and dentate gyrus compared with 
the same regions in vehicle-treated animals. Coadministration of IGF-2 blocked the neuroprotective effects of IGF-1 and reduced the accumulation of IGF-I in the injured hemisphere and these observations suggest a role for IGFBPs in targeting the neuroprotective actions of IGF1. IGF-2 may antagonize the protective effect of IGF-1 by displacing it from IGFBPs [37]. On the other hand $[25,38,39]$. AD patients were also reported to have increased fasting glucose and insulin concentrations, thus indicating insulin resistance in $\mathrm{AD}$ etiology; glucose utilization is decreased in $\mathrm{AD}$, as are the glucose-transporters GLUT-1 and GLUT-3 levels in the brains of AD patients; an emerging body of evidence suggests that an increased prevalence of insulin abnormalities and insulin resistance in AD may contribute to the disease; in AD patients hyperinsulinism induced without hyperglycemia significantly enhances memory [40-44]. However, the accumulating evidence that reduced glucose utilization and deficient energy metabolism occur early in the course of disease, suggests a role for impaired insulin signaling in the pathogenesis of AD. There are extensive abnormalities in insulin and IGF-I and II signaling mechanisms in brains with $\mathrm{AD}$, and show that while each of the corresponding growth factors is normally made in central nervous system neurons, the expression levels are markedly reduced in AD. These abnormalities were associated with reduced levels of insulin receptor substrate (IRS) mRNA, tau mRNA, IRS-associated phosphotidylinositol 3-kinase, and phospho-Akt (activated), and increased glycogen synthase kinase-3beta activity and amyloid precursor protein mRNA expression. The strikingly reduced expression of central nervous system genes encoding insulin, IGF-I, and IGF-II, as well as the insulin and IGF-I receptors, suggests that $\mathrm{AD}$ may represent a neuroendocrine disorder that resembles, yet is distinct from diabetes mellitus. Regulation of brain Abeta by insulin has a double-sided effect on brain. It stimulates neuronal release of Abeta, and at the same time contributes to the extra neuronal accumulation of Abeta by competing for the insulindegrading enzyme that degrades insulin and Abeta. The ultimate activity of insulin is to increase brain Abeta. The effect of IGF-I in Abeta clearance is mediated by enhancing the transport of the Abeta carrier proteins, albumin and transthyretin into the brain through the choroid plexus, with increased levels of Abeta in the cerebrospinal fluid and this process is blocked by tumor necrosis factor $\alpha(\mathrm{TNF} \alpha)$ [42].

Therefore, it has been proposed the term, "type 3 diabetes" to reflect this identified pathogenic mechanism of neurodegeneration [44]. In previous studies, adults AD showed memory enhancement when plasma insulin levels were raised, whereas normal adults memory was unchanged. Degree of memory enhancement was also related to apolipoprotein E genotype status for AD patients. Response differences between normal and $\mathrm{AD}$ groups could reflect dose-response differences for insulin.

Both insulin and IGF-I belong to the same protein family and are important modulators of brain function and the ability of insulin/IGF-I to modulate neuronal excitability and synaptic plasticity underlies the modulatory effects of these hormones on cognitive processes. Evidence favoring this idea stems from the ability of both hormones to stimulate Abeta amyloid release from neurons as well as by the stimulatory effect that IGF-I exerts on brain amyloid clearance. In addition, insulin and IGF-I levels are altered in $\mathrm{AD}$ and, probably in close association to these changes, cell sensitivity towards insulin--and possibly also IGF-I is decreased in these patients. There is evidence that disturbed insulin/IGF-I signaling to brain cells, initiated at the level of the blood-brain barriers is probably instrumental in development of brain amyloidosis. Furthermore, insulin and IGF-I are potent neuroprotective factors and can regulate levels of phosphorylated tau, a major component of neurofibrillary tangles found in AD brains. Therefore, a decrease in trophic support to neurons together with increased tau phosphorylation will follow loss of sensitivity towards insulin and IGF-I. Altogether, this supports the notion that a single pathogenic event, i.e., brain resistance to insulin/IGF-I, accounts for neuronal atrophy/death, tangle formation and brain amyloidosis typical of $\mathrm{AD}$ pathology $[45,46]$.

Insulin not only regulates blood sugar concentrations but also acts as a growth factor on all cell including neurons in the central nervous system. Brain resistance to insulin/IGF-I accounts for neuronal atrophy and death, tangle formation and brain amyloidosis typical of AD pathology [47]. The cytokine TNF $\alpha$ and IGF-I have both been shown to regulate inflammatory events in the central nervous system. The independent roles of TNF $\alpha$ and IGF-I in promoting and inhibiting neurodegenerative diseases. There is evidence that the combined effects of IGF-I and TNF $\alpha$ on neuronal survival can be vastly different when both receptors are stimulated simultaneously, as is likely to occur in vivo. There is a framework of a molecular model of hormone-cytokine receptor cross talk in which disparate cell surface receptors share intracellular substrates that regulate neuronal survival [47].

\section{IGF-BINDING PROTEINS IN ALZHEIMER'S DISEASE}

IGF-binding proteins (IGFBPs) have been shown to have an essential role in the regulation of cell survival, not only through regulation of free bioactive IGFs, but also via several IGF-independent effects. In particular, IGFBP-3 has been shown to induce apoptosis and inhibit cell growth independently of IGFs. IGFBP-3 rapidly translocates to the nucleus, where it specifically and functionally interacts with nuclear proteins, including the nuclear retinoid receptor, $\mathrm{RXR} \alpha$. In addition, IGFBP-3 is up-regulated by proapoptotic signal transduction pathways, including TNF $\alpha$, transforming growth factor $\beta$, and the tumor suppressor p53. The functional roles of IGFBPs in the central nervous system are still being unraveled. The expression of IGFBPs is known to change in the central nervous system in response to various insults. Recently IGFBP-3 mRNA and protein expression was shown to be significantly up-regulated in $\mathrm{AD}$ brain tissue and in response to Abeta exposure in human brain pericytes in vitro. This up-regulation of proapoptotic IGFBPs may contribute to neuronal degeneration and apoptosis and subsequently to neuronal loss and clinical symptoms in AD. 
Importantly, IGF-I-induced neuronal protection against Abeta in vitro is IGFBP-3-sensitive: IGFBP-3 abolishes IGF-I-induced survival. In a study, the authors demonstrate the interaction between IGFBP-3 and an AD-related survival peptide named humanin.

Humanin is a recently described AD-related survival peptide of major therapeutic potential. This survivalpromoting peptide was cloned from a cDNA library extracted from surviving neurons of the occipital lobe of AD brain and was shown to potently and specifically inhibit neuronal death induced by exogenous Abeta and expression of familial AD mutant genes. Recently, humamin was shown to bind the proapoptotic Bcl-2 family member, Bax, and convey part of its antiapoptotic effects through inhibition of Bax activation. The novel factor, termed humanin, antagonizes neurotoxicity by various types of familial AD genes which are mutants of amyloid precursor protein with a clear action specificity, inactivating neurotoxicity by polyglutamine repeat or superoxide dismutase 1 mutants, and which can also inhibit neurotoxicity by other AD-relevant insults; humanin makes ineffective other familial AD genes, such as amyloid precursor protein stimulation, anti-amyloid precursor protein antibody, and other $\beta$-amyloid peptides [48-50].

\section{MECHANISMS OF ACTION OF INSULIN-LIKE GROWTH FACTOR IN ALZHEIMER'S DISEASE}

Based on decreased IGF-I concentrations in AD, some authors have suggested that disrupted IGF-I input to the brain may be involved in the pathogenesis of amyloidosis and changed IGF-I signalling may potentially lead to amyloidosis [48]. Disrupting IGF-I signalling in the coroid plexus is sufficient to trigger pathological changes as those observed in $\mathrm{AD}$ and brain Abeta increases as consequence of its lower clearance.

IGF-I resistance at the blood-brain barrier is also a pathogenic event in $\mathrm{AD}$ and local alterations in IGFBPs together with altered cytokine signalling, especially TNF $\alpha$ production, may therefore lead to a loss of IGF-I input at the blood-brain barriers in AD. Alzheimer-associated neuronal thread protein (AD7c-NTP), is a protein that accumulates in cortical neurons and co-localizes with phospho-taucontaining cytoskeletal lesions in brains with AD; The results suggest that reduced survival in neurons that overexpress may be mediated by impaired insulin/IGF-1 signaling, and that CNS neurons with abundant insulin or IGF-I receptors may be particularly vulnerable to the adverse effects of AD7c-NTP [51]. Alpha-secretase cleavage of the APP is of great interest because it prevents the formation of the Alzheimer-linked amyloid- $\beta$ peptide. APP belongs to a conserved gene family including the two paralogues APPlike protein 1 and 2 . IGF-I stimulates the shedding of all three proteins. IGF-I-induced shedding of both APP and Alzheimer- linked amyloid- $\beta$ ta peptide1 is dependent on phosphatidylinositol 3- kinase, whereas Alzheimer-linked amyloid- $\beta$ peptide 2 shedding is independent of this signaling pathway [52]. Some results show that IGF-I receptor and insulin receptor signalling is compromised in $\mathrm{AD}$ neurons and suggest that neurons that degenerate in $\mathrm{AD}$ may be resistant to IGF-I receptor and insulin receptor signalling [53]. Therefore, a common signaling cascade now seems to link aging to age-associated pathologies of the brain, suggesting that pharmacologic approaches aimed at the modulation of this pathway can serve to delay the onset of age-associated disorders and improve the quality of life. Work from a wide range of fields performed with different approaches has already identified some of the signaling molecules that act downstream of IGF-I receptor, and has revealed that a delicate checkpoint exists to balance excessive growth/"immortality" and reduced growth/"senescence" of a cell [54]. Impairments in IGF-I and IGF-I receptor expression and function have been associated with increasing $\mathrm{AD}$ with dependent reductions in insulin, IGF-I, and IGF-II receptor binding, ATP levels, and choline acetyltransferase expression. Further studies have demonstrated the following: that choline acetyltransferase expression increases with insulin or IGF-I stimulation; that choline acetyltransferase is expressed in insulin and IGF-I receptor-positive cortical neurons; and that choline acetyltransferase co-localization in insulin or IGF-I receptorpositive neurons is reduced in AD. Together, these data provide further evidence that $\mathrm{AD}$ represents a neuroendocrine disorder that resembles a unique form of diabetes mellitus (type 3?) and progresses with severity of neurodegeneration [55] (Table 1).

Table 1. Characteristics of IGF-I in Alzheimer's Disease (AD)

1. Postmortem investigations revealed decreased expression of IGF-I in $\mathrm{AD}$ brains.

2. IGF-I is a potent neurotrophic as well as neuroprotective factor found in the brain: it is pleiotropic with a wide range of actions.

3. IGF-I is a critical promoter of brain development and neuronal survival

4. IGF-I is actively transported through the blood-brain barrier. Transport of peripheral IGF-I across the blood-brain barrier is accomplished by receptor-mediated transport across endothelial cells.

5. IGF-I reverses the effects of amyloid and amyloid-induced neurotoxicity.

6. IGF-I is also produced in endothelial and smooth muscle cells.

7. The high expression of IGF-I in vasculature has led to propose that both GH and IGF-I have an important role in blood vessel growth and repair.

8. IGF-I and also humanin protect the neurons of the amyloid precursor protein toxicity.

9. IGF-I concentrations have been seen to be low in family members carrying the APP 670/671 mutation, with or without AD disease.

Abeta deposition in cerebral blood vessel walls that is one of the key features of $\mathrm{AD}$. The investigation of the effects of insulin on Abeta-induced degeneration, as it has been mentioned previously that insulin is able to protect neurons against Abeta-induced cell-death. The toxic effect of DAbeta1-40 on human brain pericytes was inhibited by insulin in a dose-dependent matter. Insulin interacted with Abeta and inhibited fibril formation of Abeta in a cell-free assay, as well as at the cell surface of human brain pericytes. The formation of a fibril network is essential for Abeta- 
induced cell death in human brain pericytes. Additionally, insulin may be involved in the regulation of Abeta fibrillization in $\mathrm{AD}[56,57]$.

On the other hand, TNF $\alpha$, is both a promoter and inhibitor of neurodegeneration. TNF $\alpha$ is a proinflammatory cytokine that promotes neuronal death in vitro as well as in vivo and TNF $\alpha$ and IGF-I are potently induced in the same areas of the central nervous system in response to neurodegenerative conditions. TNF $\alpha$ is also implicated in a a variety of degenerative diseases including AD [40]. An emerging possibility is that this cytokine and IGF-I interact with each other [41]. AD is associated with dysregulation of proinflammatory cytokines in the brain and serum TNF $\alpha$ and an haplotype for TNF $\alpha$ is associated with AD [40] but the role of TNF $\alpha$ in $\mathrm{AD}$ is not clear; in experimental studies has been demonstrated that only one concentration of TNF $\alpha$ is protective over neurons, while the neuroprotective effects of IGF-I are linear and that the interactions between IGF-I and $\mathrm{TNF} \alpha$ receptors may exceed the relevance of their individual roles. TNF $\alpha$ production may promote neurodegeneration not through direct killing of neurons but rather through inhibition of IGF-I survival signalling [41,42].

\section{GROWTH HORMONE IN ALZHEIMER'S DISEASE}

In subsequent studies, administration of GHRH, to increase endogenous release of $\mathrm{GH}$, or direct administration of IGF-I was shown to reverse the age-related decline in spatial working and reference memory. Similarly, antagonism of IGF-I action in the brains of young animals impaired both learning and reference memory. Investigation of the mechanisms of action of IGF-I suggested that this hormone regulates age-related alterations in NMDA receptor subtypes (e.g. NMDAR2A and R2B). The beneficial role of GH and IGF-I in ameliorating vascular and brain ageing are counterbalanced by their wellrecognised roles in age-related pathogenesis. Although research in this area is still evolving, the decreases in GH and IGF-I with age have both beneficial and deleterious effects. Furthermore, part of the actions of moderate calorie restriction on tissue function and lifespan may be mediated through alterations in the GH/IGF-I axis [58]. Chronic GH deficiency, coupled with the decline in skeletal muscle mass and protein synthesis, contributes to frailty in the elderly and suggests that the hormonal deficiency may be a factor in age-related disability. IGF-I has an important trophic role in neuronal function and limits neuronal loss after ischemic damage [37]. The majority of evidence suggests that $\mathrm{GH}$ does not cross the blood-brain barrier although it is known that hypophysectomy decreases both GH and IGF-I mRNA in brain which are restored by GH administration Some studies suggest that GH treatment improves alertness, vitality, mood, and induces a sense of wellbeing, Some studies demonstrates that quality of life measured through Questions on Life Satisfaction-Hypopituitarism is maintained during long-term GH replacement therapy of adults with GHD, so evaluation of quality of life should be a part of the routine clinical management of adult GH-deficient patients, complementing the measurement of surrogate biological markers or other clinical end points $[59,60]$.

\section{GROWTH HORMONE RESPONSE IN ALZHEI- MER'S DISEASE}

Neuroendocrine regulation of growth hormone in $\mathrm{AD}$ is more selectively and severely damaged in $\mathrm{AD}$ patients than in other dementias [59]. Primary or secondary alterations in somatotrophic cells are also present in aged mammals, such as a reduction in the number of $\mathrm{GH}$-immunoreactive structures or post-receptor alterations. In aged rats, major alterations in brain neurotransmitters and neuropeptides are present in hypothalamic and extrahypothalamic structures, especially in catecholaminergic and acetylcholinergic neurones. These alterations are probably due to defects in neurosecretory GHRH and somatostatin neurones. GHRH synthesis is impaired in the hypothalamus of senescent male rats, as shown by a reduction in GHRH mRNA levels and GHRH-like immunoreactivity. Although the expression of somatostatin seems to decrease with age in the rat hypothalamus, secretion and activity of this hormone is increased, resulting in an altered relationship between GHRH and somatostatin gene expression and secretion. Catecholamines induce GH release in most animal species by stimulating GHRH neurones and inhibiting somatostatinreleasing neurones. Acetylcholine stimulates GH release via muscarinic receptors, and thus inhibits the effect of somatostatin neurones. In male rats of various ages, except very young rats, systemic administration of pilocarpine, an agonist of muscarinic receptors, potentiates the GH response to GHRH during the entire lifespan $[5-8,60]$. So, the hypothesis that the abnormal functioning of some of these neuropeptides systems may contribute to the symptoms of $\mathrm{AD}$ is supported by some studies [6,61-63].

Some authors have indicated that neuroendocrine regulation of GH is more selectively and severely damaged in $\mathrm{AD}$ patients than in patients suffering from other dementias at the hypothalamus [61], but at the present level of knowledge it is not possible to single out any of these changes as being of especial significance for the disease; it seems likely that the changes are secondary to more fundamental alterations in the brain [62]. The cerebrospinal fluid somatostatin level was significantly lower in patients with $\mathrm{AD}$ than in normal elderly persons, but it did not differ in young normal subjects. These results suggest that central vasopressinergic activity may be decreased in $\mathrm{AD}$ and confirm reports of low somatostatin cerebrospinal fluid levels in AD. The cerebrospinal fluid somatostatin level was significantly lower in patients with $\mathrm{AD}$ than in normal elderly persons, but it did not differ in young normal subjects $[2,6,7,61,62]$. this decrease is more severe in patients with an earlier age of AD onset [63]. To clarify the functional state of the somatotropinergic system in patients with $\mathrm{AD}$ and in patients with vascular dementia in relation with somatostatin cerebrospinal levels the GH response to GHRH in controls and in $\mathrm{AD}$ and vascular dementia patients have studied and correlated their responses with somatostatin cerebrospinal levels and no difference between the $\mathrm{AD}$ and vascular dementia patients in GH response to GHRH was observed and also no difference in somatostatin cerebrospinal levels in these patients [64].

Findings of several studies addressing this point show varied results [61,65-69], but in a sudy the proportion of patients with exaggerated, normal, or lower GH response 
was similar in the four groups of patients sith dementia, AD, parkinsonism with dementia, progressive supranuclear palsy with dementia and dementia of vascular origin in terms of TSH response to TRH, nor was there a correlation between TSH response to TRH and sex, stage of the disease, cerebral atrophy, or GH response to GHRH. The proportion of those with exaggerated, normal, or lower TSH response was similar in the four groups. Cerebrospinal somatostatin levels were similar in $\mathrm{AD}$ and vascular dementia patients. These findings indicate that neither GH response to GHRH nor TSH response to TRH provides a useful diagnostic adjunct in $\mathrm{AD}$ patients [70-72]

The presence of IGF-I and IGFBPs in the cerebrospinal fluid and serum samples was confirmed using Western blot using anti-IGF-I and IGFBPs antibodies and using enzyme linked immunosorbent assay, it was shown that the concentration of cerebrospinal fluid and serum IGF-I and IGFBPs in the patients with $\mathrm{AD}$ is higher than in normal control. The data from this study indicate that IGF-I is a constant component of human cerebrospinal fluid. It is also concluded that high levels of cerebrospinal fluid IGF-I may be partly related to AD pathophysiology [ 2,6,73-75].

$\mathrm{AD}$ is also associated with significant structural and functional changes in the noradrenergic system and the GH response to clonidine challenge reflects the sensitivity of the post-synaptic (2- noradrenergic receptors while decreased activity of pre-synaptic noradrenergic neurons has been associated with an augmentation of the GH response to clonidine. Blunted $\mathrm{GH}$ response to clonidine reflects noradrenergic overactivity that has been demonstrated in normal ageing. When AD patients were divided into those with preserved $\mathrm{GH}$ response and those with blunted $\mathrm{GH}$ response, patients with blunted response showed higher levels of aggression [10]. These findings are consistent with compensatory down-regulation of post-synaptic (2adrenergic receptors in response to noradrenergic outflow in aggressive AD patients [75,76].

\section{RELATIONSHIP AMONG ALZHEIMER'S DISEASE TREATMENT, INSULIN-LIKE GROWTH FACTOR-I SYSTEM AND GROWTH HORMONE RESPONSE TO STIMULI}

$\mathrm{AD}$ is characterized by the abnormal extracellular accumulation of Abeta into neuritic plaques and the intraneuronal aggregation of the microtubule-associated protein tau to form neurofibrillary tangles. These molecular events are implicated in the selective damage to neural systems critical for the brain functions that are impaired in AD. No antiamyloid therapies are currently available and treatment is based on neuroprotective approaches, antioxidants, anti-inflammatory agents, acetylcholinestarase inhibitors, the management of neuropsychiatric symptoms and behavioral disturbances, and general medical treatment. Impairment of cholinergic neurotransmission may be an important factor underlying the defects in cognition and memory that characterize AD. Cholinesterase inhibitors, such as donepezil, rivastigmine, and galantamine, cause symptomatic improvement by inhibiting the breakdown of the neurotransmitter acetylcholine to increase its synaptic availability and, in the case of galantamine, by also allosterically potentiating nicotinic cholinergic receptors. Other agents, including vitamin $\mathrm{E}$, monoamine oxidase inhibitors, and statins, have shown some benefit in epidemiological studies and clinical trials although compelling evidence of their efficacy is lacking. Memantine, shown to cause cognitive and functional improvement, is not an cholinesterase inhibitor and does not interact with marketed cholinesterase inhibitors. While the mechanism of action of memantine in $\mathrm{AD}$ is not known, the principal pharmacologic actions at therapeutic dose are inhibition of ionotropic neurotransmitter receptors, specifically N-methylD-aspartate, 5-HT3, and nicotinic receptors.

Acetylcholinestarase inhibitors are approved for the treatment of mild-to-moderate AD from 1994 and should be considered as a standard of care for $\mathrm{AD}$ patients. Four acetylcholinestarase inhibitors are available: tacrine, donezepil, rivastigmine, and galantamine, and pivotal clinical trials have shown changes on the tests such as ADAS-cog (Alzheimer's Disease Assessment Scale cognitive subscale) that may be reflected in changes in daily life [77-79]. This fact may help affected patients to maintain with significant benefits their ability to perform everyday activities [80]. The combination of acetylcholinestarase inhibitors with memantine, is superior to acetylcholinestarase inhibitor monotherapy [81-83].

Several attempts have been made to reverse the manifestations of the senile GH deficiency, termed somatopause, but GH substitution treatment in old age has not yet developed an established regimen. Cholinesterase inhibitors like pyridostigmine are able to elicit GH secretion when administered alone and to enhance the $\mathrm{GH}$ response to GHRH, but its clinical use is limited due to the strong peripheral cholinergic side effects. Rivastigmine is a powerful drug to enhance GH release to repeated GHRH stimulation in healthy elderly human subjects. Future investigations are necessary to find out whether rivastigmine can restore the senile decline of the circadian GH secretion in the long term and, therefore, has new implications for patient treatment. Althougt, some studies showed that when rivastimine was acutely administered, the area under the curve of the GH response to GHRH nearly doubles, showing that rivastigmine is a powerful drug for enhancing $\mathrm{GH}$ release $[70,82,83]$. In controls, subsequent to 8 weeks of treatment with the very well-tolerated selective acetylcholinestarase inhibitor donezepil, the area under the curve of the GH response to GHRH increased by $52 \%$, and, remarkably, IGF-I concentrations increased by $28 \%$, which means a significant and probably clinically relevant shift of IGF-I concentrations to those that are seen in younger subjects Cholinesterase inhibitors enhance cholinergic transmission indirectly, by inhibiting the enzyme which hydrolyses acetylcholine. It has been also demonstrated that acetylcholinesterase is involved in the development of amyloid plaques. Therefore, substances which are acetylcholinesterase inhibitors are the only drugs approved for the symptomatic treatment of AD. Among them there is a very interesting group dual binding site inhibitors characterized by increased inhibitory potency against 
acetylcholinesterase and amyloid plaques formation. There is also a group of compounds with additional properties such as: antioxidant activity, affinity to 5-HT(3) receptors, inhibition of $\mathrm{N}$-methyltransferase that metabolize histamine, which can be beneficial for the treatment of $\mathrm{AD}$. Furthermore there are some interesting compounds which belong to different chemical groups also of natural origin. In this review we sum up current research concerned with development of acetylcholinesterase inhibitoris which can be more effective in the future treatment of $\mathrm{AD}$ [84-87]. Huperzine, a novel alkaloid isolated from the Chinese herb Huperzia serrata, is a potent, highly specific a reversible inhibitor of acetylcholinestarase with higher oral bioavailability than tacrine, donezepil, and rivastigmine, and longer duration of action; improves cognitive deficits and these protective effects are related to its ability to attenuate oxidative stress, regulate the expression of apoptotic proteins, $\mathrm{Bcl}-2, \mathrm{Bax}, \mathrm{p} 53$, and caspase-3, protect mitochondria, up regulate nerve growth factor and its receptors, and interfere with amyloid precursor protein metabolism [88-92]. In an analysis of 59 studies, both acetylcholinestarase inhibitors and memantine had consistent effects in the domains of cognition and global assessment, but outcomes in the domains of behavior and quality of life were evaluated less frequently and showed less consistent effects. The analysis concluded that treatment of dementia with acetylcholinestarase inhibitors and memantine can result in statistically significant but clinically marginal improvement in measures of cognition and global assessment of dementia $[93,94]$.

\section{POSSIBLE USEFULNESS OF GROWTH HORMONE/ INSULIN-LIKE GROWTH FACTOR-I AXIS IN ALZHEIMER'S DISEASE TREATMENT}

The transport mechanism for IGF-I in choroid plexus involves the IGF-I receptor and the membrane multicargo transporter megalin/LRP2. Pharmacological modulation of IGF-I transport by megalin may be used to increase brain availability of serum IGF-I. Interestingly, GSK3 inhibitors such as those under development to treat Alzheimer's disease may show therapeutic efficacy in part by increasing brain IGF-I levels, an effect already reported for other neuroprotective compounds [95-97].

Some authors show that IGF-I increases (-secretase processing of endogenous amyloid precursor protein and the amyloid precursor-like proteins 1 and 2 [36,97-100]. Avenues and bases for further investigation have been exposed in an effort to further understanding of $A D$ and other neurodegenerative diseases. However, the poor availability of IGF-I, and its penetration of the brain, hampers progress in this regard [101]. On the other hand, the $\mathrm{GH}$ secretagogue receptor is a target of new drugs that can reverse the age- related reduction in the amplitude of GH pulsatility and IGF-I concentrations, as has been demonstrated with MK-0677, whose effects over the GH/ IGF-I axis were sustained and accompanied by a better lean/fat ratio and a modest increase in strength [85]. IGFBP3 has been shown to have a function in the regulation of cell survival via several IGF-independent effects; in particular, it has been shown to induce apoptosis. ical assessment improved with an increase in cerebrospinal concentrations of monoamine metabolites and somatostatin [102,103]. In conclusion, the available symptomatic therapies for the treatment of $\mathrm{AD}$ have been based on known neurotransmitter dysfunctions associated with AD. Meta-analyses of these therapies, focusing on their effectiveness and tolerability showed that although many of the studies demonstrate statistically significant improvements, the question remains as whether if these benefits are sufficient to justify their current widespread and protracted use. Consequently, an emerging clinical targets for improving the quality of life with ageing or for improving clinical manifestations of $\mathrm{AD}$ may be activation of GH/IGF-I axis.

\section{CONFLICT OF INTEREST}

The author confirm that this article content has no conflict of interest.

\section{ACKNOWLEDGEMENT}

Declared none.

\section{REFERENCES}

[1] McKhann G, Drachman D, Folstein M, et al. Clinical diagnosis of Alzheimer's disease: report of the NINCDS-ADRDA Work Group under the auspices of Department of Health and Human Services Task Force on Alzheimer's disease. Neurology 1984; 34: 939-44.

[2] Müller EE. Neural control of somatotropic function. Physiol Rev 1987; 67: 962; 1053-8.

[3] Patel K, Dixit VD, Lee JH, et al. Identification of ghrelin receptor blocker, D-[Lys3] GHRP-6 as a CXCR4 receptor antagonist. Int J Biol Sci 2012; 8: 108-17.

[4] Butterfield DA. Amyloid beta-peptide (1-42)-induced oxidative stress and neurotoxicity: implications for neurodegeneration in Alzheimer's disease brain. A review. Free Radic Res 2002; 36: 1307-13.

[5] Davis KL, Mohs RC, Marin DB, et al. Neuropeptide abnormalities in patients with early Alzheimer's disease. Arch Gen Psychiatry 1999; 56: 981-7.

[6] Atack JR, Beal MF, May C, et al. Cerebrospinal fluid somatostatin and neuropeptide $\mathrm{Y}$. Concentrations in aging and in dementia of the Alzheimer type with or without extrapyramidal signs. Arch Neurol 1988; 45: 269-74.

[7] Gottfries CG. Neurochemical aspects of dementia disorders. Dementia Ger Cogn Dis 1990; 1: 56-64.

[8] van de Nes JAP, Sandmann-Keil D, Braak H. Interstitial cells subjacent to entorthinal region expressing somatostatin-28 immunoreactivity are susceptible to development of Alzheimer's disease-related cytoskeletal changes. Acta Neuropathol (Berl) 2002; 104: 351-6.

[9] Winsky-Sommerer R, Grouselle D, Rougeot C, et al. The proprotein convertase $\mathrm{PC} 2$ is involved in the maturation of prosomatostatin to somatostatin-14 but not in the somatostatin deficit in Alzheimer's disease. Neurosci 2003; 122: 437-47.

[10] Mattews KL, Chen CP, Esiri MM, et al. Nordadrenergic changes, aggresive behavior, and cognition in patients with dementia. Biol Psychiatry 2002; 51: 407-16.

[11] Heilig M, Sjögren M, Blennow K, et al. Cerebrospinal fluid neuropeptides in Alzheimer's disease and vascular dementia. Biol Psychol 1995; 38: 210-6.

[12] Nyberg F. Opioid peptides in cerebrospinal fluid-method for analysis of their significance in the clinical perspective. Front Biosci 2004; 9: 3510-25.

[13] San Frutos M, Cacicedo L, Méndez C, et al. Pituitary alterations involved in the decline of growth hormone gene expression in the pituitary of aging rats. J Gerontol Biol 2007; 62A: 585-97. 
[14] Corpas E, Harman SM, Piñeyro MA, et al. Human growth hormone and human ageing. Endocrine Rev 1993; 14: 65-71.

[15] Gómez JM, Maravall FJ, Gómez N, et al. Interactions between serum leptin, insulin-like growth factor-I system, and sex, age, anthropometric and body composition variables in a healthy population randomly selected. Clin Endocrinol (Oxf) 2003; 58: 213-9.

[16] Gómez JM, Maravall FJ, Gómez N, et al. Reduced IGF-I and free IGF-I in obesity: modulation by sex, age, body mass index and body fat. Growth Horm IGF Res 2004; 14: 91-6.

[17] Le Roith D, Bondy C, Yakar S, et al. The somatomedin hypothesis: 2001. Endocrine Rev 2001; 22: 53-74.

[18] Frytsk J, Vetbo E, Skjaebaek C, et al. Free insulin-like growth factors in human obesity. Metabolism 1995; 44: 37-44.

[19] Van Dam PS, Aleman A, de Vries WR, et al. Growth hormone, insulin-like growth factor I and cognitive function in adults. Growth Horm IGF Res 2000; 10 (Suppl B): S69-73.

[20] Sonntag WE, Ramsey M, Carter ChS. Growth hormone and insulin-like growth factor-I (IGF-I) and their influence on cognitive aging. Ageing Res Rev 2005; 4: 195-212

[21] Cacicedo L Sánchez-Franco F. GH and IGFI system and cerebral aging. Endocrinol Nutr 2010; 57: 235-9.

[22] Moloney AM, Griffin RJ, Timmons S, et al. Defects in IGF-1 receptor, insulin receptor and IRS-1/2 in Alzheimer's disease indicate possible resistance to IGF-1 and insulin signalling. Neurobiol Aging 2010; 31: 224-43.

[23] Landi F, Capoluongo E, Russo A, et al. Free insulin-like growth factor-I and cognitive function in older persons living in community. Growth Horm IGF Res 2007; 17: 58-66.

[24] Chapman IA, Hartman ML, Pieper KS, et al. Recovery of growth hormone release from suppression by exogenous insulin-like growth factor (IGF-I): evidence for a suppressive action of free rather than bound IGF-I. J Clin Endocrinol Metab 1998; 83: 283642.

[25] Rollero A, Murialdo G, Fonzi S, et al. Relationship between cognitive function, growth hormone and insulin-like growth factor I plasma levels in aged subjects. Neuropsychobiology 1998; 38: 739.

[26] Burman P, Deijen JB. Quality of life and cognitive functions in patients with pituitary insufficiency. Psychother Psychosom 1998; 7: 154-67.

[27] Deijen JB, de Boer H, van der Veen EA. Cognitive changes during growth hormone replacement in adult men. Psychoneuroendocrinology 1998; 23: 45-55.

[28] Niikura T, Yamada M, Chiba T, et al. Characterization of V642IAbetaPP-induced cytotoxicity in primary neurons. J Neurosci Res 2004; 77: 54-62

[29] Mustafa A, Lannfelt L, Lilius L, et al. Decreased plasma insulinlike growth factor-I level in familial Alzheimer's disease patients carrying the Swedish APP 670/671. Dementia Ger Cogn Dis 1991; 82: $2836-42$

[30] Busiguina S, Fernández AM, Barrios V, et al. Neurodegeneration is associated to changes in serum insulin-like growth factors. Neurobiol Dis 2000; 7: 657-65.

[31] Dik MG, Pluijm SMF, Jonker C, et al. Insulin-like growth factor I (IGF-I) and cognitive decline in older persons. Neurobiol Ageing 2003; 24: 573-81.

[32] Murialdo G, Barreca A, Nobili F, et al. Relationship between cortisol, dehydroepiandrosterone sulphate and insulin-like growth factor-I system in dementia. J. Endocrinol Invest 2001; 24: 136-46.

[33] Grimwood K, Veith RC. Enhancement of memory in Alzheimer disease with insulin, somatostatin, but not glucose. Arch Gen Psychiatry 1999; 56: 1135-40.

[34] Dore S, Kar S, Quirion R. Insulin-like growth factor I protects and rescues hippocampal neurons against beta-amylin and human amylin-induced toxicity. Proc Natl Acad USA 1997; 94: 4772-7.

[35] Dore S, Batianetto S, Kar S, et al. Protective and rescuing abilities of IGF-I and some putative radicals scavengers against betaamyloid-inducing toxicity in neurons. Ann N Y Acad Sci 1999; 890: 356-64.
[36] Dore S, Kar S, Zheng WH, et al. Rediscovering good old friend IGF-I in the new millenium: possible usefulness in Alzheimer's disease and stroke. Pharm Acta Helv 2000; 74: 273-80.

[37] Guan J, Williams CE, Skinner SJ, et al. The effects of insulin-like growth factor (IGF)-1, IGF-2, and des-IGF-1 on neuronal loss after hypoxic-ischemic brain injury in adult rats: evidence for a role for IGF binding proteins. Endocrinology 1996; 137: 893-8.

[38] Araki W, Kume H, Oda A, et al. IGF-1 promotes beta amyloid production by a secretase-independent mechanism. Biochem Biophys Res Commun 2009; 380: 111-4.

[39] Papadakis MA, Grady D, Tierney MJ, et al. Insulin-like growth factor I and functional status in healthy older humans. J Am Geriatr Soc 1995; 43: 1350-5.

[40] Collins JS, Perry RT, Watson B, et al. Association of a haplotype for tumor necrosis factor in siblings with late-onset Alzheimer disease: the NIMH Alzheimer disease genetics initiative. Am J Med Genet 2000; 96: 823-30.

[41] Craft S, Asthana S, Cook DG, et al. Insulin dose-response effects on memory and plasma amyloid precursor protein in Alzheimer's disease: interactions with apolipoprotein $\mathrm{E}$ genotype. Psychoneuroendocrinology. 2003; 28: 809-22.

[42] Pickering M, Cumiskey D, O'Connor JJ. Actions of TNF-alpha on glutamatergic synaptic transmission in the central nervous system. Exp Physiol 2005; 90: 663-70.

[43] Craft S, Asthana S, Newcomer JW, et al. Insulin effects on glucose metabolism, memory, and plasma amyloid precursor protein in Alzheimer's disease differ according to apolipoprotein-E genotype. Ann N Y Acad Sci 2000; 903: 222-8.

[44] Steen E, Terry BM, Rivera EJ, et al. Impaired insulin and insulinlike growth factor expression and signaling mechanisms in Alzheimer's disease- is this type 3 diabetes?. J Alzheimer Dis 2005; 7: 63-70.

[45] Li L, Hölscher C. Common pathological processes in Alzheimer disease and type 2 diabetes: a review. Brain Res Rev 2007; 56: 384-402.

[46] Carro E, Torres-Alemán I. The role of insulin and insulin-like growth factor $\mathrm{I}$ in the molecular and cellular mechanisms underlying the pathology of Alzheimer's disease. Eur J Pharmacol 2004; 490: 127-33.

[47] Gasparini L, Xu H. Potential roles of insulin and IGF-I in Alzheimer's disease. Trends Neurosci 2003; 26: 404-6.

[48] Carro E Trejo JL, Gómez-Isla T, et al. Serum insulin-like growth factor I regulates brain amyloid-beta levels. Nat Med 2002; 8: 1390-7.

[49] Ikonen M, Liu B, Hashimoto Y, et al. Interaction between the Alzheimer's survival peptide humanin and insulin-like growth factor-binding protein 3 regulates cell survival apoptosis. Proc Natl Acad Sci USA 2003; 100: 13042-4.

[50] Hahimoto Y, Niikura T, Sudo H, et al. Detailed characterization of neuroprotection by a rescue factor humanin against various Alzheimer's disease-relevant insults. J Neuroscien 2001; 21: 9235 45 .

[51] de la Monte SM, Wands JR. Alzheimer-associated neuronal thread protein mediated cell death is linked to impaired insulin signalling. J Alzheimer Dis 2004; 6: 231-4.

[52] Jacobsen KT, Adlerz L, Multhaup G, et al. Insulin-like growth factor-1 (IGF-1)-induced processing of amyloid-beta precursor protein (APP) and APP-like protein 2 is mediated by different metalloproteinases. J Biol Chem 2010; 285: 10223-31.

[53] Moloney AM, Griffin RJ, Timmons S, et al. Defects in IGF-1 receptor, insulin receptor and IRS-1/2 in Alzheimer's disease indicate possible resistance to IGF-1 and insulin signalling. Neurobiol Aging 2010; 31: 224-43.

[54] Puglielli L. Aging of the brain, neurotrophin signaling, and Alzheimer's disease: is IGF1-R the common culprit?. Neurobiol Aging 2008; 29: 795-811.

[55] Rivera EJ, Goldin A, Fulmer N, et al. Insulin and insulin-like growth factor expression and function deteriorate with progression of Alzheimer's disease: link to brain reductions in acetylcholine. J Alzheimers Dis 2005; 8: 247-68.

[56] Renksink AAM, Gellekink H, Otte-Höller I, et al. Expression of the cytokine leukemia inhibitory factor and pro-apoptotic insulin- 
like growth factor binding protein-3 in Alzheimer's disease. Acta Neuropathol (Berl) 2002; 104: 525-33.

[57] Buckbinder L, Talbott R, Velasco-Miguel S, et al. Induction of the growth inhibitor IGF-binding protein 3 by p53. Nature 1995; 377 : 646-9.

[58] Sonntag WE, Lynch C, Thornton $\mathrm{P}$, et al. The effects of growth hormone and IGF-1 deficiency on cerebrovascular and brain ageing. J Anat 2000; 197: 575-85

[59] Rosilio M, Blum WF, Edwards DJ, et al. Long-term improvement of quality of life during growth hormone $(\mathrm{GH})$ replacement therapy in adults with $\mathrm{GH}$ deficiency, as measured by questions on life satisfaction-hypopituitarism (QLS-H). J Clin Endocrinol Metab 2004; 89: 1684-93.

[60] Mesa J, Gómez JM, Henández C, on behalf of Spanish collaborative group. Growth hormone deficiency in adults: effects of replacement therapy on body composition and health-related quality of life. Med Clin (Barc) 2003; 120: 41-6.

[61] Müller EE, Cella SG, De Gennaro Colonna V, et al. Aspects of the neuroendocrine control of growth hormone secretion in ageing mammals. J Reprod Fertil Suppl 1993; 46: 99-114.

[62] Raskind MA, Peskind ER, Lampe TH, et al. Cerebrospinal fluid vasopressin, oxytocin, somatostatin, and $\beta$-endorphin in Alzheimer's disease. Arch Gen Psychiatry 1986; 43: 382-8.

[63] Patel YC. General aspects of the biology and function of somatostatin. In: Weil C, Müller EE, Thorner MO, Eds. Somatostatin. Berlin: Springer Verlag 1992; pp. 29-42.

[64] Cacabelos R, Niigawa H, Ikemura Y, et al. GHRH-induced GH response in patients with senile dementia of the Alzheimer type. Acta Endocrinol (Copenh) 1988; 117: 295-301.

[65] Gómez IM, Aguilar M, Navarro MA, et al. GH response to GHreleasing hormone $(\mathrm{GHRH})$ in Alzheimer and vascular dementia. Relation with somatostatin cerebrospinal levels. Ann Endocrinol (Paris) 1996; 57: 107-10.

[66] Gómez Sáez JM, Aguilar Barberá M. GH response to GH-releasing factor in dementia and its relation with $\mathrm{TSH}$ response to $\mathrm{TSH}-$ releasing factor. Dementia Ger Cogn Dis 1991; 2: 173-6.

[67] Gómez Sáez JM, Fernández Real JM, Navarro MA, et al. GH secretion status in myotonic dystrophy. Psychoneuroendocrinology 1993; 18: 183-90.

[68] Gómez JM, Aguilar M, Navarro MA, et al. Secretion of growth hormone and thyroid-stimulating hormone in patients with dementia. J Mol Med 1994; 72: 489-93.

[69] Gómez JM, Aguilar M, Soler J. Growth hormone and thyrotropin hormone secretion in Alzheimer's disease. J Nutr Health Aging 2000; 4: 229-32.

[70] Obermayr RP, Mayerhofer L, Knechtelsdorfer M, et al. The reduced release of GH by GHRH in 8 subjects aged 65-69 years is augmented considerably by rivastigmine, a drug for Alzheimer's disease. Gerontology 2003; 49: 191-5.

[71] Ghigo E, Nicolosi M, Arvat E, et al. Growth hormone secretion in Alzheimer's disease: studies with growth hormone releasing hormone alone and combined with pyridostigmine or arginine. Dementia Ger Cogn Dis 1993; 4: 315-20.

[72] Herrmann N, Lanctôt KL, Eryave G, et al. Growth hormone response to clonidine predicts aggression in Alzheimer's disease. Psychoneuroendocrinology 2004; 29: 1192-7.

[73] Nilsson CL, Brinkmalm A, Minthon L, et al. Processing of neuropeptide Y, galanin, and somatostatin in the cerebrospinal fluid of patients with Alzheimer's disease and frontotemporal dementia. Peptides 2001; 22: 2105-12.

[74] Lal S, Nair NP, Thavundayil JX, et al. Growth hormone response to apomorphine, a dopamine receptor agonist, in normal aging and in dementia of the Alzheimer type. Neurobiol Aging 1989; 10: 22731.

[75] Salehi Z, Mashayekhi F, Naji M. Insulin like growth factor-1 and insulin like growth factor binding proteins in the cerebrospinal fluid and serum from patients with Alzheimer's disease. Biofactors 2008; 33: 99-106.

[76] Delgado-Rubin A, Chowen JA, Argente J, et al. Growth hormonereleasing peptide 6 protection of hypothalamic neurons from glutamate excitotoxicity is caspase independent and not mediated by insulin-like growth factor I. Eur J Neurosci 2009; 29: 2115-24.
[77]

Ritchie CW, Ames D, Clayton T, et al. Metaanalysis of randomized trials of the efficacy and safety of donazepil, galantamine, and rivastigmine for the treatment of Alzheimer's disease. Am J Geriatr Psychiatry 2004; 12, 358-69.

[78] Cummings JL. Drug therapy. Alzheimer's disease. N Engl J Med 2004; 351: 56-67.

[79] Doraiswamy PM, Krishnan KRR, Nemeroff CB. Neuropeptides and neurotransmitters in Alzheimer's disease: focus on corticotrophin releasing factor. Ball Clin Endocrinol Metab 1991; 5: 59-77.

[80] Edwards K, Therriault O'CJ, Gorman C. Switching from donezepil or rivastigmine to galantamine in clinical practice. J Am Geriatr Soc 2004; 52: 1965-72.

[81] Farlow MR. Clinical pharmacokinetics of galantamine. Clin Pharmcokinet 2003; 42: 138: 3-98.

[82] Obermayr RP, Mayerhofer L, Knechtesdorfer M, et al. The agerelated down-regulation of the growth hormone/insuli-like growth factor- 1 axis in the elderly male is reversed considerably by donezepil, a drug for Alzheimer's disesase. Exp Gerontol 2005; 40: 157.

[83] Zizzari P, Bassabt HH, Pointdessous- Jazat F, et al. Donezepil restores $\mathrm{GH}$ secretion in old rats withoyr affecting the sleep/wake cycle. Nuerobiol Aging 2006; 27: 784-90.

[84] Huber ER, Obermayr R, Madersbacher S, et al. Growth hormone, insulin-like growth factor-1 and growth hormone response to growth hormone releasing hormone in the elderly male augmented considerably by donezepil, a drug for Alzheimer's disease. Eur Urol 2004; (Suppl. 3): 63-76.

[85] Smith RG. The ageing process: where are the drug opportunities. Curr Opin Chem Biol 2000; 4: 371-6.

[86] Musial A, Bajda M, Malawaska B. Recent developments in cholinesterases inhibitors for Alzheimer's disease treatment. Curr Med Chem 2007; 14: 2654-79.

[87] $\mathrm{Yu} \mathrm{H}, \mathrm{Li} \mathrm{W}-\mathrm{M}, \mathrm{Kan} \mathrm{KKW}$, et al. The physicochemica I properties and in vivo $\mathrm{AChE}$ inhibition of two potential anti-Alzheimer agent, bis(12)-hupyridone and bis(7)-tacrine. J Pharm Biomed Anal 2008; 46: 75-81.

[88] Wang R, Wang S, Malter JS, et al. Effects of HNE-modification induced by Abeta on neprilysin expression and activity in $\mathrm{SH}$ SY5Y cells. J Neurochem 2009; 108: 1072-82.

[89] Muñoz-Ruiz P, Rubio L, García-Palomero E, et al. Design synthesis, and biological evaluation of dual binding site acetylcholinesrase inhibitors; new disease-modifying agents for Alzheimer's disease. J Med Chem 2005; 48: 7223-33.

[90] Sellal F, Nieoullon A, Michel G, et al. Pharmacology of Alzheimer's disease: where do we go from here? Therapie 2005; 60: 89-107.

[91] Onor ML, Trevfisol M, Aguglia E. Rivastigmine in the treatment of Alzheimer's disease: an update. Clin Intern Aging 2007; 2: 17-32.

[92] Gómez JM. In The somatotrophic axis in brain function. Nyberg, F. Ed. San Diego, USA: Elsevier Inc. 2006; pp. 301-10.

[93] Qaseem A, Snow V, Cross Jr T, et al. Current pharmacologic treatment of dementia: a clinical practice guideline from the American College of Physicians and the American Academy of Family Physicians. Ann Intern Med 2008; 148: 370-8.

[94] Raina P, Santaguida P, Smaila A, et al. Effectiveness of cholinesterase inhibitors and memantine for treating dementia: evidence review for a clinical practice guideline. Ann Intern Med 2008; 148: 379-97.

[95] Carro E, Torres-Aleman I. Insulin-like growth factor I and Alzheimer's disease: therapeutic prospects? Rev Neurother 2004; 4: 76-86.

[96] Araki W, Kume H, Oda A, Tamaoka A, Kametani F. IGF-1 promotes beta-amyloid production by a secretase-independent mechanism. Biochem Biophys Res Commun 2009; 380: 111-4.

[97] Bolós M, Fernandez S, Torres-Aleman I. Oral administration of a GSK3 inhibitor increases brain insulin-like growth factor I levels. J Biol Chem 2010; 285: 17693-700.

[98] Lopez-Lopez C, Dietrich MO, Metzger F, et al. Disturbed cross talk between insulin-like growth factor I and AMP-activated protein kinase as a possible cause of vascular dysfunction in the 
amyloid precursor protein/presenilin 2 mouse model of Alzheimer's disease. J Neurosci 2007; 27: 824-31.

[99] Singh M, Arseneault M, Sanderson T, et al. Challenges for research on polyphenols from foods in Alzheimer's disease: bioavailability, metabolism, and cellular and molecular mechanisms. J Agric Food Chem 2008; 56: 4855-73.

[100] McNamee P, Vanoli A, Hutchings D, et al. Savings from subgroupspolicy guidance and Alzheimer' s disease treatments. J Nutr Health Aging 2010; 14: 664-8.
[101] Chaudhry U, Zhuang H, Doré S. Microsomal prostaglandin E synthase-2: cellular distribution in Alzheimer's disease. Exp Neurol $2010 ; 223: 359-65$.

[102] Doggrell SA. The potential of activation of somatostatinergic neurotransmission with FK960 in Alzheimer's disease. Expert Opin Invest Drugs 2004; 13: 67-72.

[103] Svennerholm L, Brane G, Karlsson I, et al. Alzheimer diseaseeffect of continuous intracerebroventricular treatment with GM1 ganglioside and a systematic activation programme. Dem Geriatr Cogn Disor 2002; 14: 128-36.

(C) José Manuel Gómez Sáez; Licensee Bentham Open.

This is an open access article licensed under the terms of the Creative Commons Attribution Non-Commercial License (http://creativecommons.org/licenses/by$\mathrm{nc} / 3.0 /$ ) which permits unrestricted, non-commercial use, distribution and reproduction in any medium, provided the work is properly cited. 